Journal of Mammalogy, Vol. 52, No. 2 (May, 1971), pp. 458-460

This document is a U.S. government work and is not subject to copyright in the United States.

PMID: 5104083

\title{
WING LOADING IN PLECOTUS RAFINESQUII
}

Considerable interest has developed in recent years with regard to studies of wing areas and wing loadings of North American bats (Davis and Cockrum, 1964; Jones, 1967; Davis, 1969; Farney and Fleharty, 1969). To our knowledge, such data have not been presented for Plecotus rafinesquii, one of the least known of North American species (Barbour and Davis, 1969). The purpose of this report is to provide information on flight of $P$. rafinesquii and to compare and discuss briefly certain aspects of flight in young and adults of this species, as well as adults of two other species of Plecotus.

Seventy-one $P$. rafinesquii were studied: five were banded and released and 66 were preserved either as skins and skulls or in fluid and deposited in the United States National Museum (USNM) or in the Vertebrate Collections of Tulane University (TU). The animals were observed and collected $12 \mathrm{mi}$. W Woodville, Wilkinson Co., Mississippi, on 11 June 1970 ( 29 USNM, 29 TU) and on the Riverside Campus of Tulane University, Plaquemines Parish, Louisiana, on 30 June and 31 July 1970 ( $8 \mathrm{TU}$ ). At the former locality bats were found in an abandoned house; at the latter site animals were located beneath old ammunition-storage bunkers.

Outlines of wings and calculations of wing areas were obtained from either live or freshkilled bats according to the procedures described by Davis (1969). Weights of animals were determined with an Ohaus triple beam balance. Data were separated according to date of collection and age of animals. Because there were few apparent differences between the sexes in wing areas, wing loadings, and weights, data for males and females were combined.

Young $P$. rafinesquii captured on 11 June were smaller, but with a corresponding greater wing loading, than adult females taken from the same maternal colony (Table 1). Forearms of 26 young bats averaged $35.01(33.4-36.9)$ millimeters long, whereas those of 32 adult females averaged $43.36(42.3-44.3)$.

At the time of capture, young $P$. rafinesquii exhibited straightline, non-agile flight and usually landed in a head up position. Young $P$. townsendii studied by Pearson et al. (1952) began flight at about 16 to 20 days of age. According to the formula for estimating age of $P$. townsendii developed by Pearson et al. (1952), we calculated that the young $P$. rafinesquii captured on 11 June were 15 to 18 days old. Our estimates of age for the young bats studied 
TABLE 1.-Arithmetic means, extremes, and standard errors of the means of weights, wing areas, and wing loadings of Plecotus rafinesquii.

\begin{tabular}{cccc}
\hline $\begin{array}{c}\text { Specimens } \\
\text { examined }\end{array}$ & \multicolumn{1}{c}{$\begin{array}{c}\text { Weight } \\
(\mathrm{g})\end{array}$} & $\begin{array}{c}\text { Wing area } \\
\left(\mathrm{cm}^{2}\right)\end{array}$ & $\begin{array}{c}\text { Loading } \\
\left(\mathrm{g} / \mathrm{cm}^{2}\right)\end{array}$ \\
\hline \multirow{3}{*}{26 young } & \multicolumn{1}{c}{ Mississippi, 11} & June 1970 & \\
& $5.58 \pm 0.133$ & $65.83 \pm 2.617$ & $0.087 \pm 0.005$ \\
32 adults & $(5.20-6.20)$ & $(47.73-73.53)$ & $(0.071-0.115)$ \\
& $8.40 \pm 0.180$ & $109.49 \pm 3.133$ & $0.074 \pm 0.002$ \\
& $(7.90-9.10)$ & $(100.62-121.59)$ & $(0.071-0.077)$ \\
5 young & Louisiana, 30 & June 1970 & \\
& $6.28 \pm 0.133$ & $101.26 \pm 5.156$ & $0.063 \pm 0.002$ \\
3 adults & $(5.50-6.80)$ & $(88.62-112.36)$ & $(0.058-0.072)$ \\
& $7.37 \pm 0.171$ & $115.32 \pm 6.057$ & $0.064 \pm 0.004$ \\
& $(7.10-7.70)$ & $(106.68-127.19)$ & $(0.057-0.069)$ \\
3 young & Louisiana, 31 & July 1970 & - \\
& - & $105.52 \pm 3.543$ & - \\
2 adults & - & $(98.69-110.81)$ & - \\
& - & 114.17 & - \\
\hline
\end{tabular}

also coincided with the limited data on birth of young in this species-mostly during late May and early June (Barbour and Davis, 1969).

Young bats observed and captured on 30 June and 31 July weighed less than adults, but young and adults were similar in wing areas and wing loadings (Table 1). No differences in flight ability were detected between the age groups. The young bats were identified easily by their dark pelage. However, the ages of young obtained in late June and July could not be estimated closely. Pearson et al. (1952) demonstrated that by 28 days of age measurements of forearms of young $P$. townsendii were similar to measurements of adults and unreliable for indicating age in young.

Adult females disturbed from the maternal colony studied on 11 June flew occasionally with attached young bats. These females flew slowly and with apparent difficulty; many were caught easily by hand. The young bats weighed from 5.2 to 6.2 grams; weights of young bats averaged 66.4 (65.8-68.1) per cent of the weights of adult females (Table 1). Pearson et al. (1952) noted that adult P. townsendii disturbed in the daytime flew with attached young weighing as much as 6.0 grams, about 66.0 per cent of the weight of the mothers. Davis and Cockrum (1964) experimentally determined weight lifting capacities of 6.8 and 7.4 grams, 72.3 and 73.3 per cent of body weight, for two female $P$. townsendii.

With the addition of the weight of attached young, the wing loading of adult $P$. rafinesquii measured on 11 June ranged from 0.126 to 0.130 grams per square centimeter. On the basis of the aforementioned observations of flight and considerations of the information available for closely related species, we estimated that the added weight of slightly more than 6.0 grams and corresponding wing loading of about 0.130 grams per square centimeter were probably near the maximum for flight of these adults.

Wing areas of adult $P$. rafinesquii captured in Mississippi in mid-June ranged (and averaged) slightly smaller than wing areas of adults measured in Louisiana in late June and July. The converse was true with regard to body weights and wing loadings; bats from Mississippi were heavier and exhibited greater loading than animals from Louisiana. The 
TABLE 2.-Arithmetic means, extremes, and standard errors of the means of wing areas and wing loadings of adults of three species of Plecotus.

\begin{tabular}{lcc}
\hline $\begin{array}{c}\text { Specimens } \\
\text { examined }\end{array}$ & $\begin{array}{c}\text { Wing area } \\
\left(\mathrm{cm}^{2}\right)\end{array}$ & $\begin{array}{c}\text { Loading } \\
\left(\mathrm{g} / \mathrm{cm}^{2}\right)\end{array}$ \\
\hline \multirow{3}{*}{10 females } & Plecotus phyllotis $($ Farney and Fleharty, 1969) & - \\
& $160.74 \pm 3.280$ & - \\
& $(144.20-177.80)$ & \\
9 males, 28 females & Plecotus townsendii (Farney and Fleharty, 1969) & $0.070 \pm 0.004$ \\
& $129.86 \pm 1.358$ & $(0.052-0.087)$ \\
& $(111.60-150.20)$ & \\
37 females & Plecotus rafinesquii (this study) & $0.069 \pm 0.007$ \\
& $112.84 \pm 2.603$ & $(0.057-0.077)$ \\
\hline
\end{tabular}

differences between these samples in body weight and corresponding wing loading probably were reflections of normal seasonal variation in body weight of bats. Adult females captured on 11 June were lactating heavily; those examined later were not lactating. For a brief discussion of seasonal variation in weight of bats, as well as some of the problems of comparing wing loading obtained from seasonally nonrandom samples, see Davis (1969).

Information on wing area and wing loading of 22 species of bats were presented by Farney and Fleharty (1969). The availability of these data permits a general comparison of some measurements of adult $P$. rafinesquii with those of other adult Plecotus (Table 2). Wing area in P. rafinesquii is smaller than in either P. townsendii or P. phyllotis; there is no overlap of 95 per cent confidence limits of the means. No data are available for $P$. phyllotis, but wing loading is similar for $P$. rafinesquii and $P$. townsendii; there is complete overlap of the 95 per cent confidence limits of the two means.

Because of possible differences in the techniques used by the investigators, we recognize that the measurements of wing areas and wing loadings given in Table 2 may not be comparable. Until additional data become available, however, the values presented provide some means for comparing certain aspects of flight in these species of Plecotus.

\section{Literature Cited}

Barbour, R. W., And W. H. Davis. 1969. Bats of America. Univ. Press Kentucky, Lexington, $286 \mathrm{pp}$.

Davis, R. 1969. Wing loading in pallid bats. J. Mamm., 50:140-144.

Davis, R., AND E. L. Cockrum. 1964. Experimentally determined weight lifting capacity in individuals of five species of western bats. J. Mamm., 45:643-644.

Farney, J., AND E. D. Fleharty. 1969. Aspect ratio, loading, wing span, and membrane areas of bats. J. Mamm., 50:362-367.

JoNEs, C. 1967. Growth, development, and wing loading in the evening bat, Nycticeius humeralis (Rafinesque). J. Mamm., 48:1-19.

Pearson, O. P., M. R. Koford, AND A. K. Pearson. 1952. Reproduction of the lumpnosed bat (Corynorhinus rafinesquei) in California. J. Mamm., 33:273-320.

Clyde Jones and Royal D. Suttkus, Bureau of Sport Fisheries and Wildlife, United States National Museum, Washington, D. C. 20560, and Department of Biology, Tulane University, New Orleans, Louisiana 70118. Accepted 4 January 1971. 